\title{
An Autopsy Case of Peripheral Neuroepithelioma in Posterior Mediastinum with p53 Point Mutation
}

\author{
Wataru Matsuyama, Joeji Wakimoto, Masanori Nakagawa*, Keiko Mizuno*, \\ Hironobu Kanazawa, Takahito Niryama*, Akira Mizoguchi, Fumiyuki Iwami, \\ Kouki YamanaKA*, Masaharu Kawabata* and Mitsuhiro OsamE*
}

\begin{abstract}
An 18-year old male was admitted to our hospital complaining of back pain. His chest computed tomography showed a tumor in the posterior mediastinum. Open biopsy was performed, and a diagnosis of peripheral neuroepithelioma was made. No genetic abnormalities were detected in the DNA obtained from the biopsy specimen. He received chemotherapy and radiation several times. These treatment regimens were effective, but he relapsed 14 months later and died of respiratory failure due to tumor growth. Autopsy examination revealed a large tumor which occupied almost the entire right thoracic cavity, but there was no evidence of metastasis to other organs. Chromosomal translocation $t(14 ; 17)(q 24 ; p 12.2)$ and point mutation of exon 5 of the $p 53$ gene were detected.
\end{abstract}

(Internal Medicine 37: 324-329, 1998)

Key words: primitive neuroectodermal tumor, Askin's tumor, $p 53$ gene, chromosomal translocation

\section{Introduction}

Peripheral neuroepithelioma (PNE) is characterized by small round cell malignancies of presumed neural crest origin arising outside the central and sympathetic nervous systems and metastasizes to extra-thoracopulmonary regions (1). Similar conditions to PNE are primitive neuroectodermal tumor (PNET) and Askin's tumor. Histopathologically, this tumor is difficult to distinguish from Ewing's sarcoma, neuroblastoma or rhabdomyosarcoma, but tentative diagnostic criteria have been proposed by Marina et al in 1989 (2). Some studies have demonstrated the associations of $p 53$ gene inactivation with human neoplasia (3) and sarcoma (4, 5) but few have shown any connections with PNE. We report here a PNE patient in the posterior mediastinum who showed no metastasis with a $p 53$ point mutation, and describe the clinical features with a review of the literature.

\section{Case Report}

An 18-year-old male was admitted to our hospital complaining of back pain that began one month previously. He had a normal birth and development, and had no family history of neoplasia. His chest $X$-ray taken one year before admission was normal. On admission, he was $168 \mathrm{~cm}$ tall and weighed $58 \mathrm{~kg}$. His blood pressure was $110 / 60 \mathrm{mmHg}$ with a pulse rate of $72 /$ min. He had no lymphadenopathy. He had no cardiac murmurs, and his chest findings were normal. Abdominal examination revealed no abnormalities. He had no pain in his limbs.

The laboratory findings on admission are shown in Table 1. He showed increased levels of alanine aminotransferase (ALT) and aspartate aminotransferase (AST). Tumor markers examined were normal except for neuron specific enolase (NSE), which was elevated to $14 \mathrm{ng} / \mathrm{ml}$ (normal, $<10 \mathrm{ng} / \mathrm{ml}$ ). Urinary levels of vanilmandelic acid (VMA) and homovanillic acid (HMA) were normal. The results of chromosomal analysis of his lymphocytes were normal. His chest X-ray film, chest computed tomography (CT) and magnetic resonance imaging (MRI) (Fig. 1, 2A, 3A, B) showed a tumor in the posterior mediastinum that arose from the intercostal nerve with invasion to the vertebrae. He had no evidence of metastasis to bone, lungs or liver.

Open biopsy was performed. The biopsy specimen showed a malignant small round cell tumor with Homer-Wright

From the Department of Respiratory Medicine, Minami-kyushu National Hospital, Kagoshima and *the Third Department of Internal Medicine, Kagoshima University School of Medicine, Kagoshima

Received for publication June 16, 1997; Accepted for publication December 22, 1997

Reprint requests should be addressed to Dr. Wataru Matsuyama, the Department of Respiratory Medicine, Minami-kyushu National Hospital, Kajiki-cho Kida 1882, Aira-gun, Kagoshima 899-5293 
Table 1. Laboratory Findings on Admission

\begin{tabular}{lrlr}
\hline Peripheral blood & & Alanine aminotransferase (ALT) & $112 \mathrm{IU} / l$ \\
White blood cell & $6,260 / \mu \mathrm{l}$ & Lactic dehydrogenase & $301 \mathrm{IU} / \mathrm{l}$ \\
Segmental neutrocyte & $51.1 \%$ & Blood urea nitrogen & $9.7 \mathrm{mg} / \mathrm{dl}$ \\
Lymphocyte & $36.4 \%$ & Creatinine & $0.5 \mathrm{mg} / \mathrm{dl}$ \\
Eosinophil & $5.6 \%$ & C-reactive protein & $0.5 \mathrm{mg} / \mathrm{dl}$ \\
Basophil & $1.1 \%$ & Erythrocyte sedimentation rate & $2 \mathrm{~mm} / \mathrm{h}$ \\
Monocyte & $5.6 \%$ & Tumor marker \\
Red blood cell & $388 \times 10^{4} / \mu \mathrm{l}$ & Carcinoembryonic antigen & $0.9 \mathrm{ng} / \mathrm{ml}$ \\
Hemoglobin & $12 \mathrm{~g} / \mathrm{dl}$ & Squamous cell carcinoma antigen & $0.7 \mathrm{ng} / \mathrm{ml}$ \\
Hematocrit & $35.5 \%$ & Neuron specific enolase & $14 \mathrm{ng} / \mathrm{ml}$ \\
Platelet & $34.7 \times 10^{4} / \mu \mathrm{l}$ & Vanilmadelic acid (in urine) & $3.5 \mathrm{mg} / \mathrm{day}$ \\
Blood chemistry & & Homovanillic acid (in urine) & $4.7 \mathrm{mg} / \mathrm{day}$ \\
Aspartate aminotransferase (AST) & $44 \mathrm{IU} / l$ & & \\
\hline
\end{tabular}
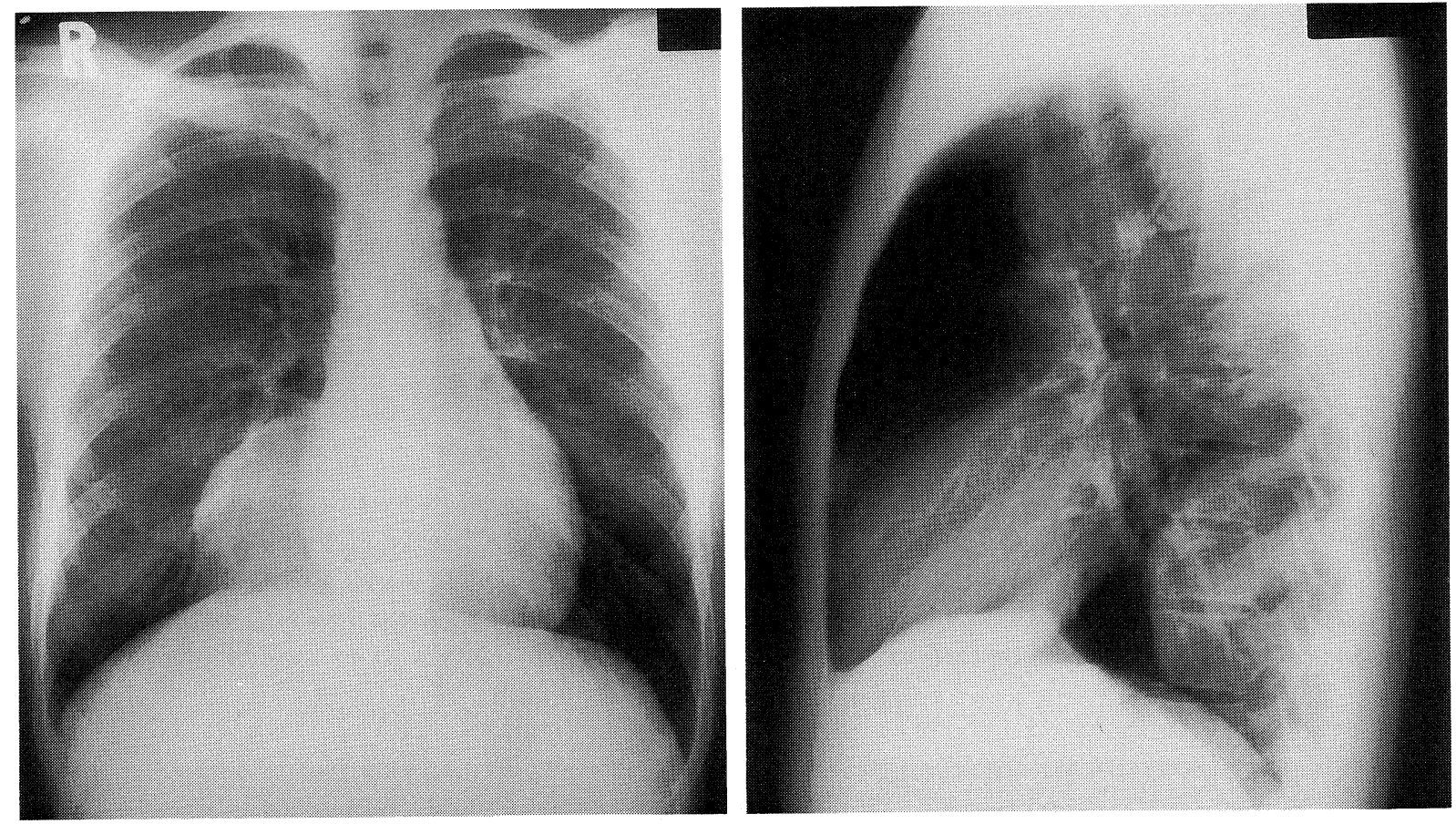

Figure 1. Chest X-ray films taken on admission showing a tumor in the posterior mediastinum.

pseudorossettes and monotonous sheets of closely opposed cells with oval and uniform nuclei (Fig. 4). Some cells showed glycogen granules by the periodic acid-Schiff (PAS) reaction. These cells were positive for NSE and negative for lymphocyte common antigen (LCA). Electron microscopy of tumor cells revealed dense core granules, measuring from 120 to $150 \mathrm{~nm}$ in diameter, which were considered to be neurosecretory granules and microtubles (Fig. 5). No abnormalities in the $p 53$ gene or amplification of the $N-m y c$ gene were detected in the DNA obtained from the biopsy specimen. Based on these clinical and pathological findings, a diagnosis of peripheral neuroepithelioma in the posterior mediastinum was made.
He underwent surgical resection of the tumor, chemotherapy (cyclophosphamide, $1,200 \mathrm{mg} / \mathrm{m}^{2}$ on day 1; etoposide, $100 \mathrm{mg}$ / $\mathrm{m}^{2}$ on day 1 to 5 ; adriamycin, $40 \mathrm{mg} / \mathrm{m}^{2}$ on day 3 ; cisplatin, 90 $\mathrm{mg} / \mathrm{m}^{2}$ on day 5 , in total 3 times every 4 weeks) and radiotherapy (Total $50 \mathrm{~Gy}$ ). Chest CT showed disappearance of the tumor (Fig. 2B), and NSE decreased to a normal level. He was discharged 4 months later. After 9 months, recurrence occurred in the right thoracic cavity which was different from the primary region (Fig. 2C). He was treated with the combination of vincristine $\left(1.4 \mathrm{mg} / \mathrm{m}^{2}\right.$ on day 1$)$, cyclophosphamide $(800 \mathrm{mg} /$ $\mathrm{m}^{2}$ on day 1$)$ and adriamycin $\left(50 \mathrm{mg} / \mathrm{m}^{2}\right.$ on day 1$)$ in total 3 times every 4 weeks. After these treatments, chest CT showed 


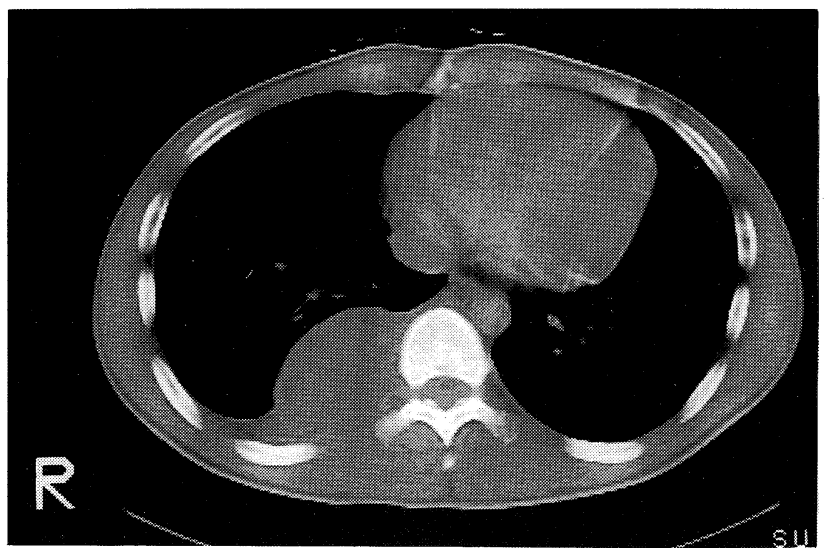

A

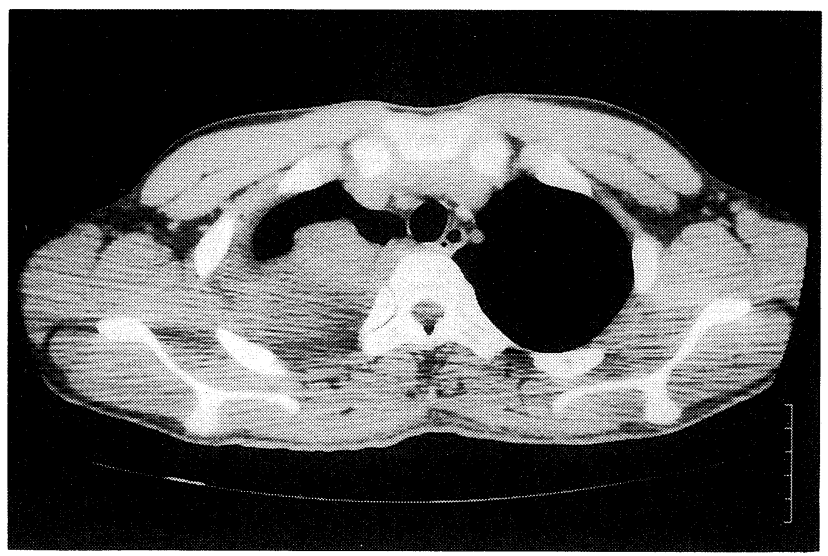

C

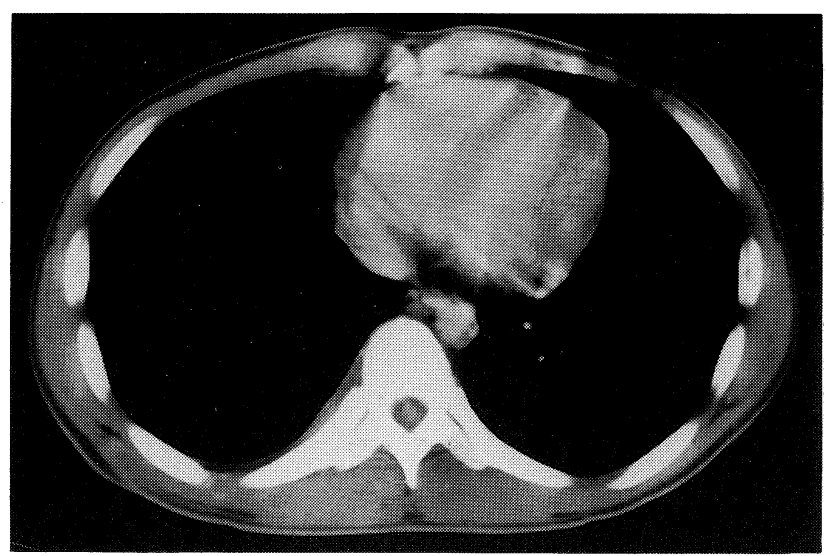

B

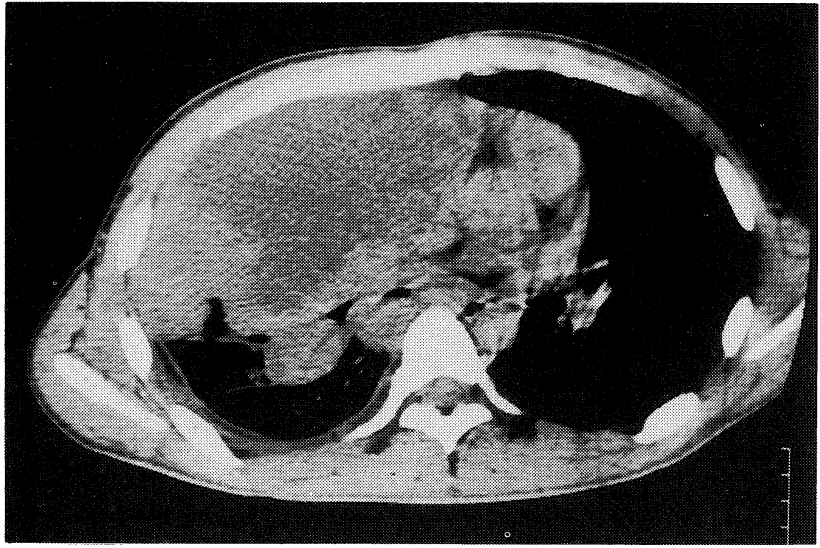

D

Figure 2. A) Chest CT on admission, showing a tumor in the right posterior mediastinum. B) Chest CT 4 months after admission, showing disappearance of the tumor. C) Chest CT 9 months after admission, showing a relapsed tumor in the right upper thoracic cavity which was different from the primary region. D) Chest CT 14 months after admission, showing a large tumor which occupied the entire right thoracic cavity with pleural effusion.

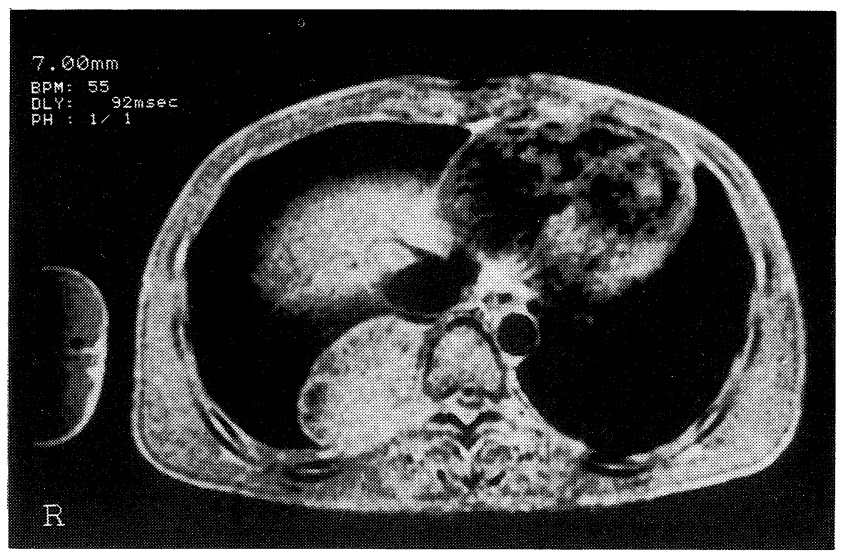

A

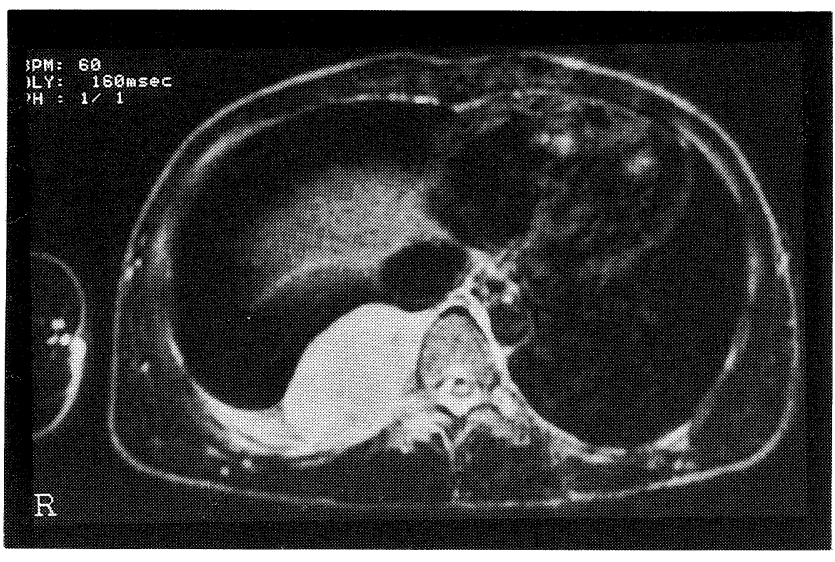

B

Figure 3. Chest MRI revealed a tumor in the posterior mediastinum which showed low intensity on T1-weighted A) and high intensity on T2-weighted MRI B). 


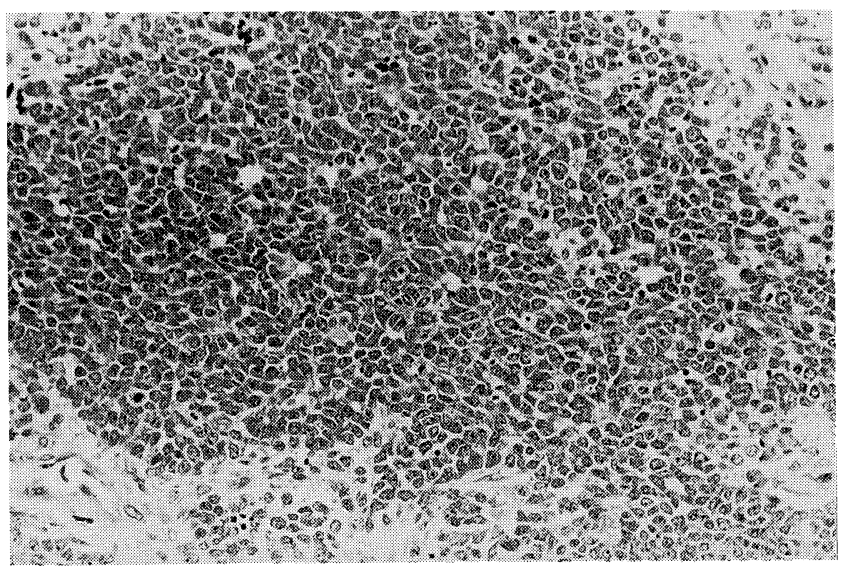

Figure 4. Hematoxylin-eosin staining of the biopsy specimen $(\times 300)$ showing a malignant small round cell tumor with HomerWright pseudorossettes and monotonous sheets of closely opposed cells with oval and uniform nuclei.

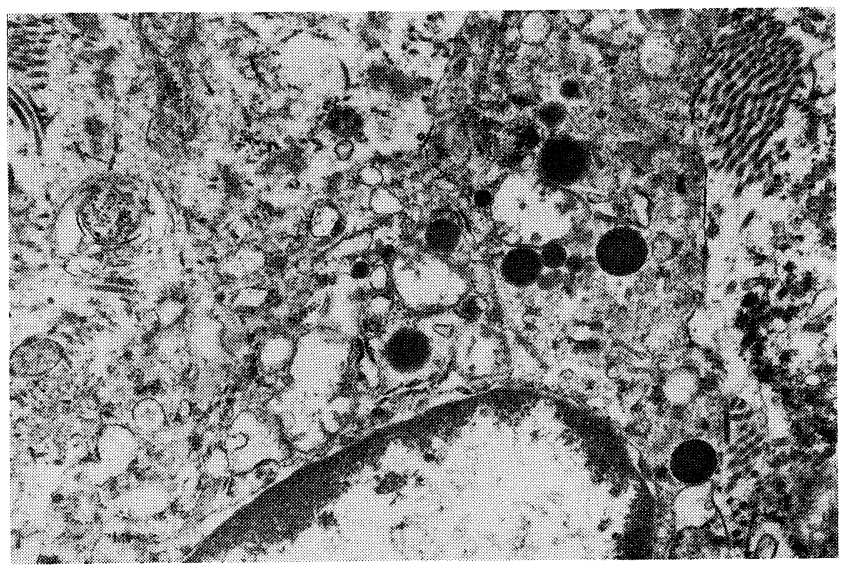

Figure 5. Electron microscopy $(\times 9,000)$ showing dense core granules measuring from 120 to $150 \mathrm{~nm}$ in diameter, which were considered to be neurosecretory granules, and microtubules.

disappearance of the tumor; but he again relapsed 14 months later. The tumor occupied almost the entire right thoracic cavity and invaded the right chest wall with pleural effusion (Fig. 2D). NSE was elevated to $140 \mathrm{ng} / \mathrm{ml}$ in serum and $940 \mathrm{ng} / \mathrm{ml}$ in pleural effusion. The chromosomal translocation $\mathrm{t}(14 ; 17)$ (q24;p12.2) was noted at this time. Radiotherapy and chemotherapy (vincristine, cyclophosphamide and adriamycin) were not effective, and he died of respiratory failure due to the tumor growth.

Autopsy examination was performed. The tumor and the necrotic tissue occupied almost the entire right thoracic cavity and expanded to the left thoracic cavity and abdominal cavity with the invasion of the right chest wall to the ribs. There was no evidence of metastasis to lungs, liver, vertebrae, bones or other organs. The primary region showed fibrosis. The autopsy

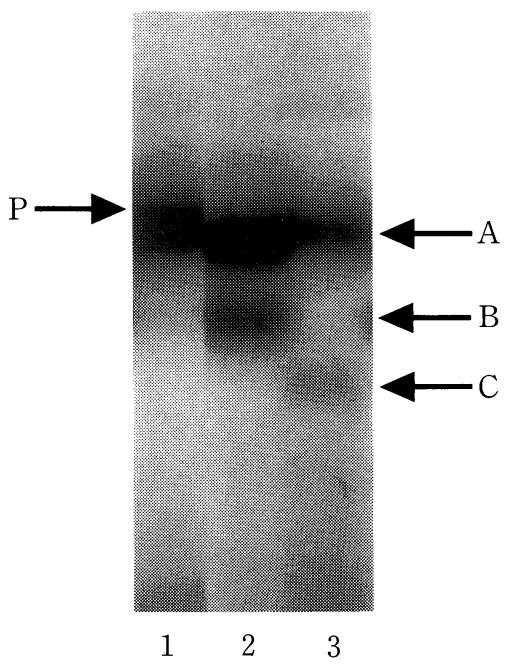

Figure 6. Polymerase chain reaction-single strand conformational polymorphism (PCRSSCP) findings of the DNA obtained from the biopsy specimen. Lane 1: patient, Lane 2: negative control, Lane 3: positive control. (A and C: normal band, $B$ : abnormal band of the positive control, P: abnormal band of the patient).
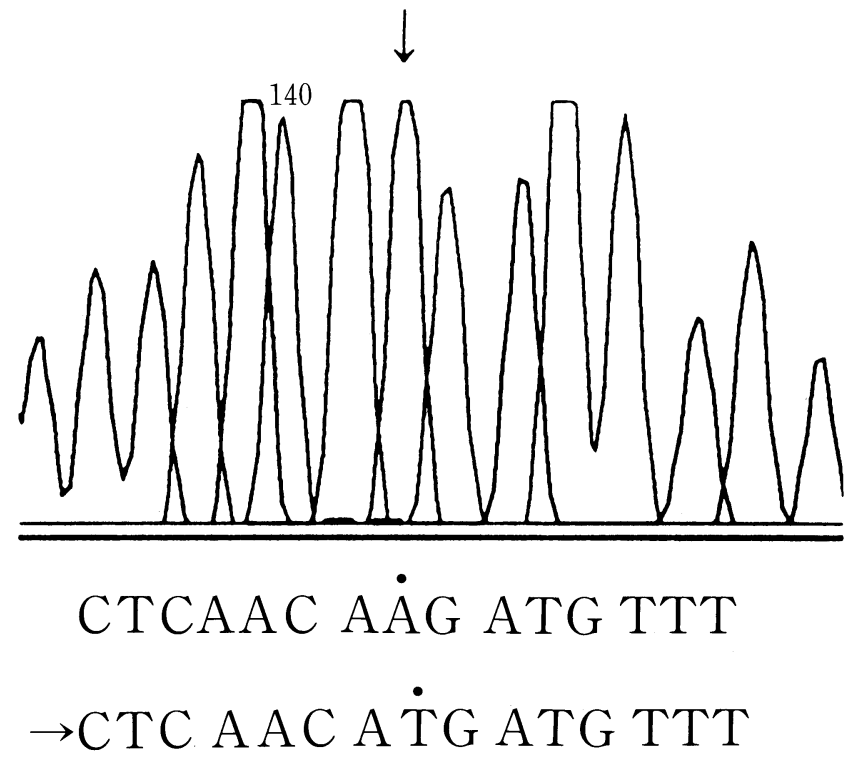

Figure 7. A point mutation at codon 132 of AAG to ATG which caused substitution of Lys to Met of the p53 exon 5 was detected by direct sequencing of the abnormal band obtained from PCR-SSCP (codon 130-134, arrow).

specimen showed the same pathological features as the biopsy specimen.

An abnormal band of $p 53$ gene exon 5 in the DNA obtained from the tumor (Fig. 6) was seen in single strand conformation 


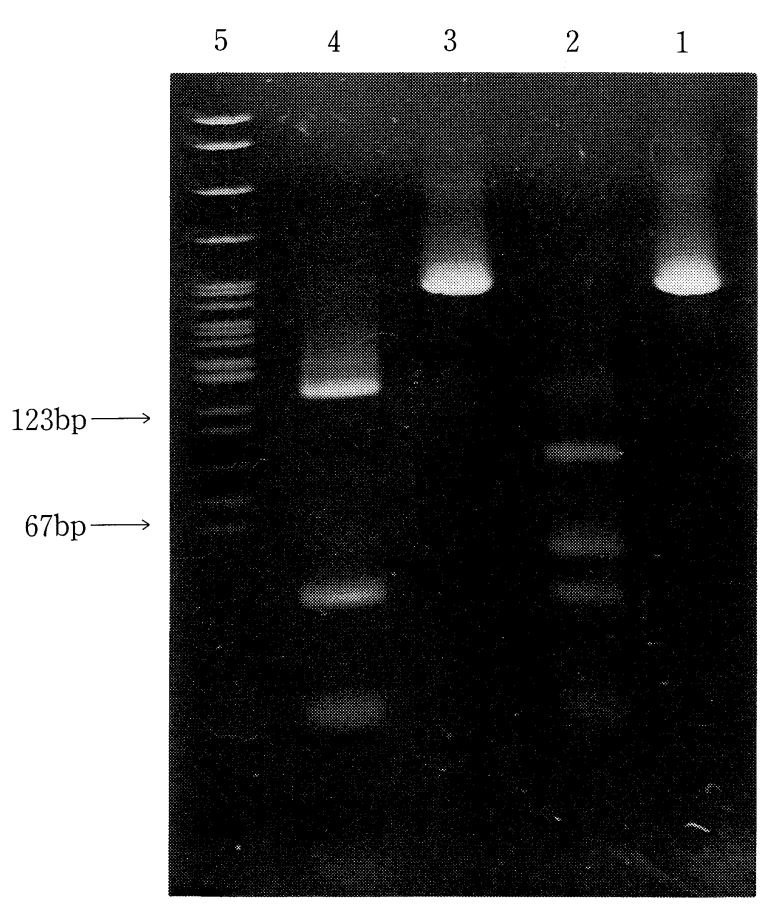

Figure 8. The PCR products amplified from the $p 53$ exon 5 region were digested with Nla III. After digestion, PCR products from the tumor DNA showed 4 bands which confirmed a new recognition site of Nla III. Lane 1: PCR product of patient, Lane 2: digestion of patient's PCR product, Lane 3: PCR product of normal control, Lane 4: digestion of normal control, Lane 5: marker.

polymorphism (PCR-SSCP) analysis and a point mutation was detected (codon132: AAG to ATG, Lys to Met) by direct sequencing (Fig. 7). However, no amplification of the $N$-myc gene was observed. The PCR products amplified from the $p 53$ exon 5 region were digested with Nla III. After digestion, PCR products from the tumor DNA showed 4 bands which confirmed a new Nla III recognition site (Fig. 8). These examinations were repeated three times and showed the same results.

\section{PCR-SSCP}

DNAs were amplified by PCR using biotinylated primers flanking the tRNA regions of $p 53$ exon 5. The amplified DNA was diluted 1:20 with $95 \%$ formamide dye solution. The mixture was heated at $80^{\circ} \mathrm{C}$ for 5 minutes, and applied at $1.5 \mu \mathrm{l} /$ lane to a $5 \%$ polyacrylamide gel containing $10 \%$ glycerol. The DNAs were electrophoresed at 40 watt for 5 hours at temperatures ranging from $14^{\circ} \mathrm{C}$ to $22^{\circ} \mathrm{C}$, and the separated DNAs were blotted on to a nylon membrane. The biotinylated DNAs were detected with a chemiluminescence detection kit (Toyobo, Tokyo).

\section{Discussion}

PNE is a group of soft tissue tumors of presumed neural crest origin that arise outside the brain, spinal cord, and sympathetic nervous system and which generally show chromosomal transformation $\mathrm{t}(11 ; 22)(\mathrm{q} 24 ; \mathrm{q} 12)$. We diagnosed the patient with PNE because of the onset age (he was too old for neuroblastoma), Homer-Wright pseudorossette formation, the positivity for NSE, the normal levels of VMA and HVA in urine, and the existence of neurosecretory granules detected by electron microscopy. PNE is predominantly located in the thoracic region, especially the ribs, followed by the extremities. However, PNE in the posterior mediastinum is very rare (6). The majority of neurogenic tumors of the posterior mediastinum in children and adolescents are neuroshwannomas and neurofibromas, and the frequency of PNE is very low (7). The tumor did not show metastasis to the extra-thoracopulmonary region, which is atypical in PNE but typical in Askin's tumor. The diagnosis of Askin's tumor was not made because the tumor arose from the posterior mediastinum which is not included in the criteria of Askin's tumor (8). Clinically, the present case is unique from two points; the first point is the primary site which is rare in PNE, and the second point is that the tumor remained in the thoracic region without metastasis.

He initially received surgery, followed by adjuvant-combined chemotherapy (cisplatin, etoposide, adriamycin and cyclophosphamide) and radiotherapy. There is no standard chemotherapy for PNE; it is performed according to the treatment for neuroblastoma. The response rate of these treatments was $75 \%$ (2), and the complete continuous remission rate was $62.5 \%$ (6). However, he relapsed 9 months later in a different region from the primary tumor which was outside of the radiotherapy area. He received only combined chemotherapy the second time, and the second relapse occupied almost the entire right thoracic cavity. These findings may suggest the effectiveness of radiotherapy in the treatment of PNE.

The pathological features of PNE have been examined in detail $(2,6)$, however, little attention has been given to its clinical and radiological aspects. Some studies have indicated that MRI is helpful for evaluating PNE in mediastinum (9), and NSE levels in pleural effusion are useful in diagnosing PNE (10). In the present case, the initial symptom was only back pain, but MRI showed a tumor that arose from the intercostal nerve and the serum level of NSE was high, especially NSE in pleural effusion at the time of relapse. Thus, MRI findings and the NSE level in serum and pleural effusion are helpful in diagnosing PNE.

The $p 53$ gene plays an important role in human neoplasia (3), and it is located in the chromosome $17 \mathrm{p}$ area (11). Some studies indicated the association of $p 53$ with human sarcoma $(4,5)$ but few have indicated any connection with PNE. One role of the p53 gene is to induce tumor cells to undergo apoptosis, and mutation of this gene is associated with poor prognosis and resistance to chemotherapy (12). The present case showed the chromosomal translocation $\mathrm{t}(14 ; 17)(\mathrm{q} 24 ; \mathrm{p} 12.2)$ and $p 53$ point mutation in exon 5. In particular, the $p 53$ point mutation was noted in the relapsed tumor and chemotherapy was not effective against the relapsed tumor. The amplification of the $N$-myc gene, which is the poor prognostic factor for sarcoma (13), was 
not detected in the tumor. The disease-free survival is $56 \% \pm$ $11 \%$ at three years in PNE patients with localized disease (6), however, the present case died about one year later despite tumor localization. Komuro et al (14) suggested that mutations of the p53 gene in Ewing's sarcoma, which has similar characteristics to PNE, might have some association with tumor progression. The significance of the $p 53$ point mutation in the present case is still unknown, but accumulation of further cases of PNE may make it clear.

Acknowledgements: We thank Shoko Taniguchi and Mutsumi Miyazaki for their excellent technical assistance.

\section{References}

1) Kushner BH, Hajdu SI, Gulati SC, Erlandson RA, Exilby PR, Lieberman $\mathrm{PH}$. Extracranial primitive neuroectodermal tumors. Cancer 67: 1825, 1991.

2) Marina NM, Etcubanas E, Parham DM, Bowman LC, Green A. Peripheral primitive neuroectodermal tumor (Peripheral Neuroepithelioma) in Children. Cancer 64: 1952, 1989.

3) Levine AJ, Momand J, Finlay CA. The $p 53$ tumour suppressor gene. Nature 351: 453, 1991.

4) Mulligan LM, Matlashewski GJ, Scrable HJ, Cavenee WK. Mechanisms of $p 53$ loss in human sarcomas. Proc Natl Acad Sci USA 87: 5863, 1990.

5) Toguchida J, Yamaguchi T, Ritchie B, et al. Mutation spectrum of the $p 53$ gene and soft tissue sarcomas. Cancer Res 52: 6194, 1992.

6) Jurgens H, Bier V, Harms D, et al. Malignant peripheral neuroectodermal tumors. A retrospective analysis of 42 patients. Cancer 61: 349, 1988.

7) Reynolds M, Shields TW. Benign and malignant mediastinal neurogenic tumors in infants and children. in: Mediastinal Surgery, Shields TW, Ed. Lea \& Febiger, Philadelphia, 1991, p. 228.

8) Askin FB, Rosai J, Sibley RK, Dehner LP, McAlister WH. Malignant small cell tumors of the thoracopulmonary region in childhood. Cancer 43: 2438, 1979.

9) Burge HJ, Novotny DB, Schiebler ML, Delany DJ, McCartney WH. MRI of Askin's tumor. Case Report at 1.5T. Chest 97: 1252, 1990.

10) Kurashima K, Muramoto S, Ohta $Y$, Fujimura M, Matsuda T. Peripheral neuroectodermal tumor presenting pleural effusion. Intern Med 33: 783, 1994.

11) Nigro JM, Baker SJ, Preisinger AC, et al. Mutations in the $p 53$ gene occur in diverse human tumour types. Nature 342: 705, 1989.

12) Fisher DE. Apoptosis in cancer therapy: Crossing the threshold. Cell 78: 539, 1994.

13) Pelicci PG, Lanfrancone L, Brathwaite MD, Wolman SA, Favere RD. Amplification of $\mathrm{N}-m y c$ in untreated human neuroblastomas correlates with advanced disease stage. Science 224: 1121, 1984.

14) Komuro $\mathrm{H}$, Hayashi $\mathrm{Y}$, Kawamura $\mathrm{M}$, et al. Mutations of the $p 53$ gene are involved in Ewing's sarcomas but not in neuroblastomas. Cancer Res 53: 5284, 1993. 